\title{
Preparing tutors for problem-based learning: An experience from B. P. Koirala Institute of Health Sciences, Nepal
}

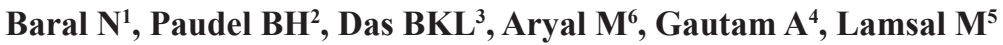

${ }^{1}$ Professor and Head, ${ }^{2}$ Additional Professor, ${ }^{4}$ Assistant Professor, Department of Health Professions Education, ${ }^{3}$ Senior Demonstrator, ${ }^{5}$ Professor, ${ }^{6}$ Department of Biochemistry, B. P. Koirala Institute of Health Sciences, Dharan, Nepal

\begin{abstract}
Background: Problem based learning (PBL) has made major impact on curricular designing and practice in medical education for the last forty years. Incorporation of PBL approach in medical education has been a challenge and opportunity for both educationists on how to impart change and medical teachers on how to internalise the change.

Objectives: This paper aimed to investigate experiences, achievement and responses of medical teachers at B. P. Koirala Institute of Health Sciences (BPKIHS), Nepal.

Materials and methods: There were 25 heterogeneous groups of teachers, majority of them were entry level. Pre- and Post- test question were taken from various topics relevant to PBL such as learning strategy and principles of adult learning, PBL practice at BPKIHS, tutorial session and role of a tutor, making resource session interactive, designing PBL problems, planning educational objectives in PBL, formulation of problem for PBL. In addition to it participants' perception on development and dissemination of PBL manual and effectiveness of workshop were also included in the questionnaire.
\end{abstract}

Results: There was significant gain in knowledge following the workshop $(p<0.001)$. The perception of the teacher found quite relevant and useful for adopting new role as tutor. The respondent teachers noted that skills they learned during the training will be applicable to their job situation. They stressed for an additional training for reinforcement and update with new trends and tools in PBL.

Conclusion: Therefore, such trainings for faculty development would be highly beneficial to inculcate new competencies in PBL.

Key words: BPKIHS, Faculty Development, Problem Based Learning

$\mathrm{P}$ roblem based learning (PBL) is the learning that results from the process of working towards understanding or resolving a problem ${ }^{1}$. At present there are many medical institutions around the globe, which have introduced PBL as an educational approach, but there is no uniformity in implementation of PBL in different schools and there are apprehensions about changing from traditional system to PBL curricula ${ }^{2}$. Some institutions are reluctant to adopt the PBL system because of lack of sufficient number of trained and motivated teachers in spite of awareness of positive aspects of PBL as a strategy of learning because pedagogic shift from traditional teaching to a studentcentred approach requires a change in the role of the educator ${ }^{3}$. Staff development is central to curricular change from a traditional to a problem-based philosophy, and there is always resistance in applying the change ${ }^{4}$.

In this regard, B. P. Koirala Institute of Health Sciences (BPKIHS) has adopted an integrated curriculum incorporating the organ-system and partial PBL approach which aims to include forward looking instructional innovation in medical education incorporating old time honoured practices with newer approaches ${ }^{5,6}$. More than 12 PBL themes, each one of one-week duration, are organised during phase one, which have basic science subjects integrated around organ-system and are interfaced with clinical disciplines ${ }^{2}$. About 20-25\% of the phase one (first two years) MBBS curriculum was covered through PBL for the last 12 years. The curriculum stresses upon small group approach to enable the students to learn concepts of small group dynamics and team work ${ }^{7}$.

Correspondence

Dr. Nirmal Baral

Professor and Head

Department of Biochemistry and Health Professions Education

B. P. Koirala Institute of Health Sciences, Dharan, Nepal

E-mail: nirmalbaral@yahoo.com 
Since most faculty members at BPKIHS have primarily lecture-based experience, they have expertise in the discipline in which they have been trained. But they have limited training for tutoring a PBL. Thus, teachers' training as a part of faculty development is considered a necessity at present circumstance and is instrumental in its implementation ${ }^{8}$.

Presently BPKIHS enrols 100 medical, 40 dental, 20 nursing students. To implement PBL for them, there is felt need for effective tutors. Therefore, Department of Health Professions Education conducted a teachers' training to provide various teaching skills, to select and design relevant problems for PBL cases. This paper presents our experiences and responses of trainees in the workshop reflecting effectiveness of three day long training -workshop in PBL at BPKIHS.

\section{Methodology}

A three day long "Training on Problem Based Learning" was held in March 2007 having eight hours of teaching interactive sessions supplemented by active group work of participant for four hours and three hours of presentation by them in front of their fellow participants, comment on them by other groups. The participants were heterogeneous group of twenty five teachers representing medical, dental, nursing and public health schools. Of the participants, 16 out of 25 were clinical teachers. Prospective tutors were selected by the respective heads of departments who are regularly participating in PBL week as a resource person as well as tutor. Many of the participants were of entry level teachers (those who have recently joined medical teaching). Pre- and post-test questions were taken from various topics. The collected data had two categories of responses: (1) a questionnaire survey of participants at the beginning and end of the workshop to determine their gain in knowledge expressed in terms of score and (2) a semi-structured questionnaire survey of participants' perception at the end of workshop to evaluate their perception on usefulness of the workshop expressed in terms of qualitative open ended responses and scores. The latter category had items with five-point Likert scale (strongly agree - 1, agree - 2, neutral option 3 , disagree -4 and strongly disagree - 5) and responses to open-ended statements to document participants general views. Scale 1 and 2 as well as 4 and 5 were merged for purpose of analysis 9 . The questionnaire was obtained from Faculty of Medicine, Maastricht University. The responses were entered into a spreadsheet and analyzed by paired 't' test, using Epi Info 2000 and MS Excel - 6 wherever applicable. A 'p' value of less than 0.05 was considered statistically significant.

\section{Results}

All the participants $(\mathrm{n}=25)$ responded to the questionnaire distributed in pre- and post-test in the study. Majority of teachers were from clinical disciplines representing 18 departments. Majority $(88 \%)$ of the faculty members were of entry and junior level teachers. There was significant gain in knowledge following the workshop ( $p<0.001)$ assessed by pretest and post-test score. The percentage of respondents for each level of agreement was calculated. The questionnaire statements are rearranged in table 1 and 2 to show the descending order from strong agreement. The majority $(96 \%)$ of respondents reported that they had a better understanding of opportunities and limitation of PBL. The participants found that training on PBL was informative (92\%). Their personal goal had been made by the program expressed by $88 \%$ of the participants. The majority ( $88 \%$ ) reported that they had learnt new thing about PBL and increased their interest in PBL. They felt that the opportunity to ask question was sufficient $(88 \%)$.

The participants expressed high degree of agreement with the most topics of PBL training workshop (Table 2 ). They expressed their agreement in designing PBL program (96\%), educational objectives in PBL (92\%), principle of adult learning (88\%), PBL at BPKIHS $(88 \%)$, adult learning strategy $(84 \%)$ and formulation of problems for PBL (84).

In general, participants were very positive about PBL workshops. They found that the training objectives were clear (68\%) and duration of training was adequate $(72 \%)$. In response to the open-ended questions, majority of participants expressed such type of training is needed for betterment of PBL and stressed for shorter session with long duration. 
Table 1: Participants' views on accomplishment of goals of PBL

\begin{tabular}{|c|c|c|c|c|}
\hline S. No. & Topics & $\begin{array}{l}\text { Agree } \\
\mathbf{n}(\%)\end{array}$ & $\begin{array}{l}\text { Neutral option } \\
\text { n(\%) }\end{array}$ & $\begin{array}{l}\text { Disagree } \\
\mathbf{n}(\%)\end{array}$ \\
\hline 1 & $\begin{array}{l}\text { Now, I have a better understanding of the opportunities and } \\
\text { limitation of PBL }\end{array}$ & $24(96 \%)$ & -- & $1(4 \%)$ \\
\hline 2 & There was sufficient opportunity for participants contributions & $23(92 \%)$ & $1(4 \%)$ & $1(4 \%)$ \\
\hline 3 & I have learned new things about PBL & $22(88 \%)$ & -- & $3(12 \%)$ \\
\hline 4 & The training has increased my interest in PBL & $21(84 \%)$ & -- & $4(16 \%)$ \\
\hline 5 & The pace in which the information was provided was adequate & $17(68 \%)$ & $7(28 \%)$ & $1(4 \%)$ \\
\hline 6 & The personal goals I had for this training was met & $15(60 \%)$ & $9(36 \%)$ & $1(4 \%)$ \\
\hline 7 & There was sufficient variation in topics during training & $12(48 \%)$ & $9(36 \%)$ & $4(16 \%)$ \\
\hline
\end{tabular}

Table 2: Participants' views on different headings/topics of PBL

\begin{tabular}{|c|l|c|c|c|}
\hline S. No. & Topics & $\begin{array}{c}\text { Agree } \\
\mathbf{n}(\%)\end{array}$ & $\begin{array}{c}\text { Neutral option } \\
\mathbf{n}(\%)\end{array}$ & $\begin{array}{c}\text { Disagree } \\
\mathbf{n}(\%)\end{array}$ \\
\hline 1 & Designing PBL program & $24(96 \%)$ & -- & $1(4 \%)$ \\
\hline 2 & Making Educational Objectives for PBL & $23(92 \%)$ & $1(4 \%)$ & $1(4 \%)$ \\
\hline 3 & Principle of Adult Learning & $22(88 \%)$ & $2(8 \%)$ & $1(4 \%)$ \\
\hline 4 & PBL in BPKIHS & $22(88 \%)$ & $2(8 \%)$ & $1(4 \%)$ \\
\hline 5 & Dissemination of PBL manual & $22(88 \%)$ & $1(4 \%)$ & $2(8 \%)$ \\
\hline 6 & Adult Learning Strategy & $21(84 \%)$ & $2(8 \%)$ & $2(8 \%)$ \\
\hline 7 & Formulation of problems of PBL & $21(84 \%)$ & $3(12 \%)$ & $1(4 \%)$ \\
\hline 8 & $\begin{array}{l}\text { Plenary session on problem formulated by participants and group } \\
\text { discussion }\end{array}$ & $21(84)$ & $3(12 \%)$ & $1(4 \%)$ \\
\hline 9 & Tutorial Session and Role of a tutor & $20(80 \%)$ & $4(16 \%)$ & $1(4 \%)$ \\
\hline 10 & Making resource session interactive & $18(72 \%)$ & $6(24 \%)$ & $1(4 \%)$ \\
\hline
\end{tabular}

Table 3: Participants' views on workshop's clarity and its duration adequacy

\begin{tabular}{|c|l|c|}
\hline S. No & Topics & Participants Perception n (\%) \\
\hline 1 & Training Objectives & $8(32 \%)$ \\
\hline & - Very clear & $17(68 \%)$ \\
\hline & - Clear & -- \\
\hline & - Not Clear & \\
\hline 2 & & \\
\hline & Duration of Training & $18(72 \%)$ \\
\hline & - Too long & $5(20 \%)$ \\
\hline & - Too Short & $2(8 \%)$ \\
\hline & & \\
\hline 3. & Training was & $28(92 \%)$ \\
\hline & -Very much informative & $1(4 \%)$ \\
\hline & - Informative & $1(4 \%)$ \\
\hline & -Less informative & \\
\hline & & \\
\hline 4 & Opportunity to ask question & \\
\hline & - Sufficient & \\
\hline
\end{tabular}




\section{Discussion}

There is abundance of literature on PBL and evaluative studies reveal that this approach of teaching-learning is entering a new phase with results supporting its superiority over traditional methods ${ }^{10}$. PBL covering a part of curriculum seems to be more appropriate in the light of cautions expressed by Albanese and Mitchell 1993 in medical school with departmental structure and limited resources ${ }^{11}$. This information could be useful for medical schools in developing countries like ours contemplating the introduction of $\mathrm{PBL}^{3,12}$. The educational goals have changed from teaching facts to helping students to learn how to find relevant information through active process of self directed learning ${ }^{13}$. PBL is an educational method which requires a number of educational skills of teacher which differ from traditional teaching skills. The role of the teacher is shifted from a presenter of knowledge to a promoter of learning. Within the educational setting, the teacher is critical variable. The preparation, orientation and motivation of today's teacher are mandatory. At the most simplistic level, the workshop presented an opportunity for faculty member to explore a new approach to their role and evidence from our results indicates positive interest shown by the teachers in PBL.

This study attempts to investigate achievement, experiences and responses of trainees in the workshop. The purpose of targeting entry level teachers was based on our assumption that after few they are going to be leaders in their disciplines and believed to be more receptive to educational concepts ${ }^{15}$. The perception of the teachers has been found quite relevant and useful to the demands in their role as tutor. As evidence to the respondent teachers noted that skills they learn during training will be extremely applicable to their job situation.

Department of Health Professions Education firmly believes that faculty development in PBL has great potential to help individual teachers significantly change their role as small group facilitator (tutor), a pivotal position in a PBL system. However, followup and impact study of such training on the quality of tutorial process is still to be evaluated in future. Without feedback from real life practice their training cycle will not be completed ${ }^{14}$.

In future we need to include additional evidence of increased effectiveness and creative teaching, by involving the students and peer group to get the feedback. They could be excellent source of information as they are the actual evaluator whether one is a good tutor or not. We could also employ additional tools (such as observational feedback from peers or educationists) to observe and record tutor performance in future to evaluate the actual tutorial.
Conclusion

Authors believe that faculty development through formal tutor training is central to inculcate new educational roles in PBL. Therefore, this study will also help future planning of tutor training in coming days.

\section{Acknowledgement}

We are thankful to Dean-Academic, resource persons of the workshop and Academic Department for facilitating this study.

\section{References}

1. Barrows HS. The tutorial process. Carbondale: Southern Illinois University, School of Medicine; 1992.

2. Bhattacharya N. Students' perceptions of problem-based learning at the B. P. Koirala Institute of Health Sciences, Nepal. Medical Education. 1998;32:407-10.

3. Maudsley G. Roles and responsibilities of the problem based learning tutor in the undergraduate medical curriculum. British Medical Journal. 1999;318:657-61.

4. Spencer JA and Jordan RK. Learner centred approaches in medical education. BMJ. 1992;318:1280-3.

5. Agrawal CS, Karki P. Evolution of the second medical school in Nepal: A case study. Medical Teacher. 1999;21:204-6.

6. Bijlani RL. An innovative exercise in Medical Education in Nepal. Trends in Medical Education. 1997;4:3-9.

7. Puri D. An Integrated Problem-based curriculum for Biochemistry Teaching in Medical Sciences. Indian Journal Clinical Biochemistry. 2002;17:52-9.

8. Baral N, Tekian A, Gelula MH. A lesson plan template for tutor training for faculty development in PBL. In: Modern Trends in Medical Education (Monograph). Kathmandu: Kathmandu Medical College; 2009. p. 15-21.

9. Olmesdahl PJ, Manning DM. Impact of training on PBL facilitators. Medical Education. 1999;33:753-5.

10. Spencer JA, Jordan RK. Learner centered approaches in medical education. British Medical Journal. 1999;318:1280-3.

11. Vernon DTA, Blake RL. Does problem based learning work? A meta-analysis of evaluative research. Academic Medicine. 1993;68:550-63.

12. Albanese MA, Mitchell S. Problem based learning: A review of literature on its outcomes and implementation issues. Academic Medicine. 1993;68:52-81. 
13. Chapagain ML, Bhattacharya N, Jain BK, Kaini KR, Koirala S, Jayawickramarajah PT. Introducing Problem-based learning into an organ system programme. Medical Teacher. 1998;20:587-9.

14. Joshi S, Pradhan A, Dixit H. Faculty opinion survey following attendance of teacher's training workshop in Kathmandu Medical College. Kathmandu University Medical Journal. 2003;2:244-51.
15. Pant DS, Shahi M, Karmacharya PC. Assessment of faculty classroom performance following teacher's training at the medical education department, Tribhuvan University Institute of Medicine. Journal of Nepal Medical Association. 2003;42:204-11.

16. Baral N, Paudel BH, Das BK, Aryal M, Das $\mathrm{BP}$, Jha $\mathrm{N}$, et al. An evaluation of training of teachers in medical education in four medical schools of Nepal. Nepal Medical College Journal. 2007;9:157-61. 